\title{
Integrated simulation of bio positive environment in a large city through the reconstruction of its recreational areas
}

\author{
Oksana Paramonova*, Ekaterina Lysova, and Natalya Yudina \\ Don State Technical University, 344010, Rostov-on-Don, Russia
}

\begin{abstract}
In the presented article, the concept of "bio-positivity" is considered as a way of returning the natural habitat to largest cities. The problem of the aesthetic unattractiveness in modern cities, the causes and consequences of rational construction without taking into account the ecological component is outlined. Various solution methods for the natural environment restoration in large cities have been proposed. Environmental friendliness and focus on preserving the environment are highlighted as the main criteria.
\end{abstract}

\section{Introduction}

Constructive solutions of the territory are bio positive only if they create new habitats for flora and fauna in the territory. In this case, the term "bio positivity" is used, which was first used by the Professor of Moscow State University of Environmental Engineering A.N. Tetior [1].

Bio positivity of recreational zones in a large city, as an integral concept, includes the main requirements for nature-saving and nature-restoring objects, that is, a combination of elements of landscaping, greening and engineering structures, organically integrated into the environment (ecosystems) [1,2].

The criteria for the bio positivity of the formed (reconstructed) territory, in our opinion, can be the following:

- non-rejection by the existing natural ecosystems (by the example of considering the ecosystem of the small river Temernik);

- lack of discharges and ingress of pollutants into the natural environment;

- adaptability (bio adaptability) of the introduced elements of landscaping and greening for the existing natural ecosystems;

- compliance of the created recreational zone with the comfort conditions and environmental safety for residents of adjacent areas in the city.

The formation of bio positive recreational zones of water bodies in a large city solves the problem of returning the natural environment by expanding the soil and vegetation part of water protection territories and creating additional landscaping of the territory. Such zones will prevent the degradation of the natural environment under the influence of

*Corresponding author: paramonova_oh@mail.ru 
anthropogenic factors and will implement the Le Chatelier-Brown principle or the principle of equilibrium displacement. The principal value lies in the fact that it allows making certain predictions regarding the evolution of a newly created system under external influence [1-3].

The created bio positive areas of the recreational zones in a large city are the complex natural, social and technical systems. In accordance with the concept of biosphere compatibility, degradation of the water bodies' natural environment in a large city in the process of ineffective production and economic activity reduces the assimilation capacity of the ecosystem and prevents the stabilization of ecosystems.

Self-sustaining development of the recreational zones' territory based on the principles of biosphere compatibility requires a mechanism for coordinating the development of housing construction in adjoining territories, organizational, technical, managerial, economic decisions in the formation of a new look during the reconstruction of recreational areas in a large city [4-7].

Management of socio-economic systems is proposed in the works of P. Davidson, N.N. Lychkina, V.N. Sidorenko, V.A. Putilova, A.V. Gorokhova, D.Yu. Katalevsky.

The methodological basis for the development of measures for the reconstruction and development of recreational areas in a large city, taking into account the reduction of anthropogenic load, is the system-dynamic approach (modeling). The advantages of the method include the ability to isolate the cause-and-effect relationship.

To obtain practically significant results when constructing such models, it is necessary to take into account the following features:

- the described system is difficult to formalize;

- a variety of factors (social, environmental, technological, economic, etc.) forms an environment where different laws operate simultaneously, the integral effect of which is difficult to predict;

- many relationships between the system elements are difficult to quantify;

- initial information is heterogeneous and, as a rule, contradictory;

- high level of concepts' uncertainty, the rules of behavior and properties that characterize the system;

- there is a possibility of changing the structure and the appearance of new system connections;

- significant influence of the anthropogenic factor on all processes occurring in the system [5-11].

The object of the study within the framework of the bio positive environment formation is the Temernik River basin, which is a complex of natural watercourses and engineering objects, which, together with the adjacent territories, constitute a significant ecological, urban planning and recreational potential for the city of Rostov-on-Don.

The aim of the study was to ensure the implementation of the ecological, city-forming and recreational functions of the water body (the Temernik River) and the adjacent territories of the Rostov-on-Don city by gradually achieving the standards for the content of pollutants in water bodies, water protection and landscape-ecological improvement of the adjacent territories in the city, ensuring safety of the population and protection of water bodies from emergencies.

\section{Materials and methods}

Research methods are based on the main provisions of system analysis, and the theory of systems modeling, analytical generalization of well-known scientific and practical results. 


\section{Results}

The first stage of research was system-dynamic modeling, including the development of a conceptual model for the situation under study.

At this stage of research, the data on the Temernik River and the adjacent territory within the boundaries of Rostov-on-Don have been collected and analyzed.

Temernik is a flat river that flows through the Rostov region and is the right tributary of the Don River. The length of the river is $33 \mathrm{~km}$, of which $18 \mathrm{~km}$ are along the territory of Rostov-on-Don. The average slope of the river is $2.3 \%$, the width of the channel is on average up to $10 \mathrm{~m}$, and the depth is $0.3-0.8 \mathrm{~m}$. The Temernik River is a natural receiver of surface runoff from urban and adjacent areas with a catchment area of $293 \mathrm{~km}^{2}$ [12].

A general analysis of the territories adjacent to the Temernik river bed within the boundaries of Rostov-on-Don showed the need to divide the territory into sections, taking into account the temporal formation, urban planning situation, and the degree of transformation.

Within the framework of the Rostov-on-Don administrative territory zoning and taking into account the maximum attractiveness of the landscape for the park zone development, we have chosen the territory of the Oktyabrsky district, shown in Figure 1.

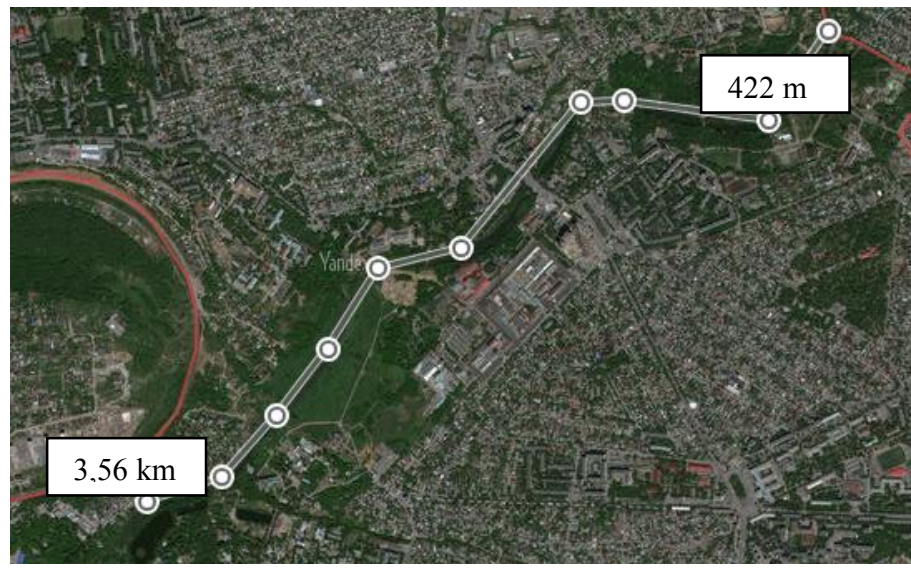

Fig.1. Study area of the Temernik river within the boundaries of the Oktyabrsky district of Rostovon-Don

Data on the survey sites' conditions were obtained during reconnaissance exits to the study area in the summer periods of 2016-2019 and included:

- characteristics of the climate and landscape in the area under study;

- hydrological conditions of the Temernik River within the study area;

- urban planning features of the river water protection zone;

- ecological assessment of environmental objects of the territory adjacent to the river;

- determination of the functional zoning of the territory and the sealing degree;

- anthropogenic load at each site by the factors of channel overgrowth, the presence and composition of runoff from residential buildings, the presence of landfill foci of spontaneous waste disposal, violation of the water protection zone boundaries, visual environment deterioration [12,13].

For the purpose of an approximate analysis of the situation development dynamics and forecasting the anthropogenic load on the territory in the city, the authors also identified the processes and phenomena that affect the surface waters pollution. At the same time, the process of the pollutants' entry into the channel of the Temernik River was studied, the types of anthropogenic impacts were determined, schemes of pollutants' flows for the 
territory of the river channel were developed, and the process of the river self-purification was analyzed $[12,13]$.

The data obtained on the Temernik River and the adjacent territory within the boundaries of Rostov-on-Don allowed us to build physical models of pollution processes and reduce water body pollution, which was the results of the first stage of research and the basis for developing measures for the environmental rehabilitation of the Temernik River [14].

The development of measures for the ecological rehabilitation of the Temernik River was started by the authors with the classification of systems for ensuring the regulatory parameters of the aquatic environment (SERPae), presented in Figure 2.

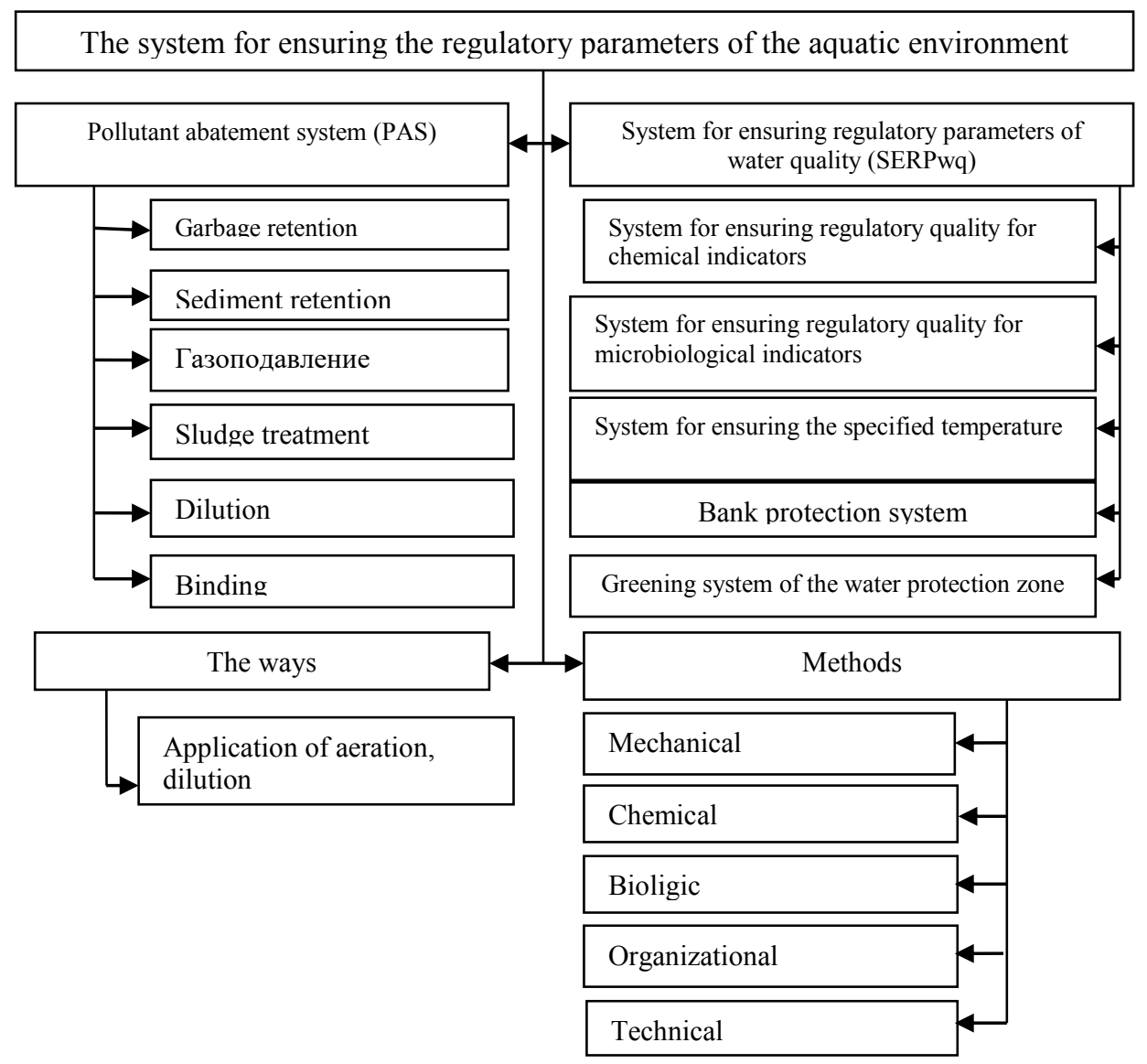

Fig. 2. System for ensuring the standard parameters of the aquatic environment

The system consists of two units: a pollutant abatement system (PAS) and a system for ensuring regulatory parameters of water quality (SERPwq).

Based on the data obtained at the first stage of research, taking into account the developed SERPae we proposed and ranked the measures for the river ecological rehabilitation, which are shown in Figure 3. 


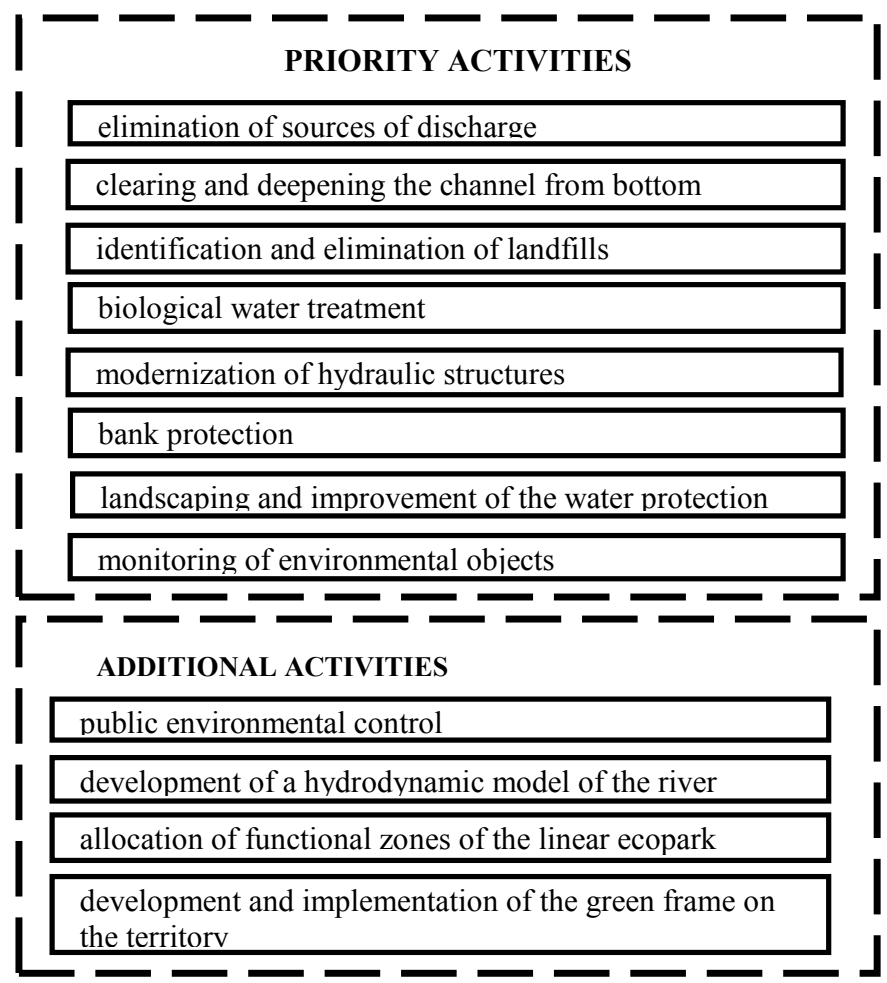

Fig. 3. Ranking of measures for ecological rehabilitation of the Temernik River in the study area

As the main regulator in the model at this stage of research, it is advisable to consider, along with priority measures, an increase in the green spaces volume, since within the boundaries of Rostov-on-Don there is no "green frame" of the city territory, which would improve the ecological state of the urban environment $[15,16]$.

\section{Conclusion}

As the basic ecological principle of the Rostov-on-Don territory development, we have chosen the principle of the territory unique natural-ecological frame development (NEF) along the small river Temernik, which runs through the entire city, with a length of $18 \mathrm{~km}$.

As a result of the natural complex study, the features and the following principles of NEF formation were revealed:

- formation of the ecological framework backbone in the territory of Rostov region (cores and corridors) due to the elements of the girder-channel network;

- development of territories included in the "forest-park green belt";

- formation of a holistic and continuous ecological framework within the city, including the territories of regulated environmental management various regimes;

- provision of conditions for creating a buffer zone of the ecological framework, based on the model of a polarized landscape $[9-11,13,15,16]$.

The proposed methodological approach makes it possible to form a block of initial data for a specific landscaping area, including information on the sanitary and ecological state of perennial vegetation, technogenic load on environmental components, to select the options for regional assortment combinations of plants that have environmental plasticity to the existing technogenic load of the territory and ensure the performance of specified functions to reduce dust load, noise level and adjust microclimate parameters. 


\section{References}

1. Alexander Tetior, Sustainable Architecture with use of soil

2. Viktoriia Sidorova, Viktoriia Zhivitsa, and Dmitry Mosyakin, Journal of Applied Engineering Science 17.2, 182-191 (2019)

3. Vitaliy Kas'yanov, and Vadim Danilchenko, Journal of Physics: Conference Series, IOP Publishing 1425, 1 (2019)

4. Astuti, Ratna Dwi Puji. Open Access Macedonian Journal of Medical Sciences 8.F, 143-154 (2020)

5. Zheng Zihao, et al. Ecological Indicators 119, (2020)

6. Halkos George, and Steriani Matsiori, Economic Analysis and Policy 58, 153-166 (2018)

7. Leone, Federica, and Corrado Zoppi, Sustainability 11.18, (2019)

8. Mahmudi Mohammad Mehdi, and Lida Eslami. "Integrated improvement strategies of deteriorated coastal cities (CASE STUDY: COAST OF BANDAR ABBAS, 2012)

9. Guo Shiyun, Shuxin Wang, and Liao Chen, Journal of Coastal Research 108.SI, 221$225(2020)$

10. Karimova Luiza Irekovna and Elena Vladimirovna Denisenko, Bulletin of Kazan State University of Architecture and Civil Engineering 1 (47), (2019)

11. Perkol-Finkel, Shimrit, et al., Ecological Engineering 120, 645-654 (2018)

12. Ecological Bulletin of Don. Report "On the State of the Environment and Natural Resources of the Rostov Region in 2018" https://docviewer.yandex.ru/view/0/?page $=2 \& *$

13. The concept of the project "Rehabilitation of the River Temernik with the arrangement of the coastal strip in the citywide Ecological Park", 2016, 2019. http://parktemernik.ru/index.php/about-2

14. Zharkova Maria, Oksana Paramonova, Natalia Yudina and Maria Balinskaya, E3S Web of Conferences 210, (2020)

15. Alisa Sokolova and Svetlana Sheina, MATEC Web of Conferences 106, (2017)

16. Yudina, Natalia, Ekaterina Lysova, Oksana Paramonova, Natalia Samarskaya, E3S Web of Conferences 135(3), (2019) 